\title{
From the Newtonian Age to the Quantum
}

Age

In the Western world at least, since the ancient Greeks, we have lived with and had all our lives, thoughts, and decisions defined by a paradigm that stresses the "reality" of separation and fragmentation. From the atoms of Democritus to those of Newton, we in the West have experienced ourselves, our organizations, and our societies as being composed of atomistic bits-body parts, minds \& bodies, individuals, departments, sectors, nation states. Today's existential climate crisis is the denouement of our 2000-year-old belief that we humans are separate from Nature, that Nature is a resource to be used by us. All of our wars and injustices have been fought or perpetrated against others who are separate from us. In our three great Western religions, even our God is portrayed as separate from us, possessing another nature or substance, not wholly fathomable to our limited human understanding. And yet we learn from both the defining principles of quantum physics, and from their much earlier expression in ancient Chinese Taoist philosophy, that both our newest physics and one of humanity's oldest traditions tell us "there is no such thing as separation," that "separation is an illusion." Everything is connected to everything, everyone is connected to everyone else. We live, they say, in a universe and in a world of zero distance.

Changes in scientific understanding often herald great changes that overtake human thinking as a whole. Science draws its inspiration from often vague and tentative but wider cultural shifts, and then transmutes these into highly focused, rigorous, clear language and into powerful 
images and metaphors. In this book I will be drawing upon the principles and philosophy of our modern science (quantum physics and complexity science), their realization in our twenty-first-century technology, and the globalized world this technology has created, to explore how to navigate and thrive in this new world of zero distance. And I will argue that the paradigm of atomistic separateness is exhausted. I believe that this exhausted paradigm, so deeply embedded in our sense of ourselves and our relationships, in the thinking behind the management and organization of our companies, and in the nature of our social and political thought, is no longer sustainable. Indeed, I believe it has caused many of the problems our leaders now struggle to solve, many of them existential threats to our very survival.

Solutions to global challenges like global pandemics, climate change, nuclear conflict, identity, populism, inequality, mass migration, the prospect of massive unemployment resulting from ever new technologies, and the economic uncertainty associated with some, or all, of these, require new thinking on a sweeping scale. As, of course, do the complexity, chaos, uncertainty, rapid change, and global interconnectivity that demand new ways of structuring and managing our companies. It is my argument here that a sweeping change of thought on this scale cannot be achieved through tinkering with piece-meal adjustments or by adopting trendy new theories. We are moving from one entire era of human civilization to another, from experiencing lives wholly framed by a now exhausted paradigm to lives yet to be framed by a new paradigm. We are, in short, in the throes of a massive paradigm shift, and it is the purpose of this book to navigate us through understanding this and to outline a guide for individuals and leaders who must "learn to build their bridge while crossing it."

\section{What Is a PARadigm Shift?}

The word "paradigm" has become so widely used and so widely misused, particularly in business circles, as nearly to have lost all meaning. Every new business guru who introduces his or her latest management theory claims to be introducing a "new paradigm." The word has come to mean no more than a "new mindset," a "new approach," a "new model," a "new idea," a "new fad," or simply "something different." These collective misrepresentations blind us to the deep, all pervasive meaning and power of a paradigm, and thus of a "paradigm shift," and thus condition 
us to pay little attention or to weaken our powers of discernment when some truly revolutionary way of understanding and experiencing our lives and our world really is demanded. If readers are to gain anything valuable from the contents of this book, it is essential you begin by understanding the correct meaning of a "paradigm" and a "paradigm shift."

The word "paradigm" was first introduced into modern usage by the University of Chicago historian of science Thomas Kuhn. In his groundbreaking book The Structure of Scientific Revolutions, ${ }^{1}$ Kuhn described a paradigm as, "the entire constellation of beliefs, values, techniques and so on shared by members of a given community." He was speaking specifically of the scientific community, the entire sense and understanding they shared when making their claims about the nature of physical reality, and the way this changed with the birth of Relativity Theory and Quantum Physics. He pointed out that this shared paradigm determined the questions they asked, the experiments they did, the observations they took from those experiments, and the meaning they assigned to them.

In the books I have been publishing since 1990, I have been among the first to point out that our scientific paradigm at any time in history, what our natural philosophers or scientists, or in ancient times our mythologies, priests \& prophets, tell us about the nature of the universe, gives rise to a more generally shared paradigm defining every aspect of how we experience and understand our human lives. In this more all-embracing meaning, a paradigm is the full sense of reality in which we are immersed. It is our sense of reality and of ourselves, body, mind, and soul. Our paradigm determines not just what we think about and how to understand our human world, but also how and what we feel, how and what we experience, and even what we detect with our five senses, most especially what we see with our eyes-what we see, and what we don't see. It determines the questions we ask and our understanding of the answers we then are given, how we view ourselves and relate to others, what is or is not worthwhile to do with our lives, even what it means to be a bad or a good person, a bad or good leader. For the vast majority of people, it is not possible to live or comprehend life and how to live it outside the constraints of the existing paradigm of the times.

But Kuhn made the very important distinction between what he called "normal science" and "revolutionary science." Normal science operates

1 Thomas Kuhn, The Structure of Scientific Revolutions, 1962. 
within the categories and understanding of the existing paradigm. Scientists assume that they know what is true and how to deepen their knowledge of it, and the experiments they then conduct are carried out to verify those assumptions. Their science is mainly an exercise in ratification and self-assurance. Each new experiment can add to their catalogue of knowledge within their existing paradigm, but nothing really surprises them. Revolutionary science, by contrast, is scientific discovery that breaks the mould, that violates existing assumptions and understanding and forces the scientist to rethink everything he thought he knew-about everything. Revolutionary science is disruptive. And it is when this kind of major disruption demands that every previous assumption now be questioned, and that all data be looked at through new eyes, that the revolutionary scientist stands at the door of a paradigm shift. Normal science, Kuhn says, goes astray,

And when it does - when, that is, the profession can no longer evade anomalies that subvert the existing tradition of scientific practice - then begin the extraordinary investigations that lead the profession at last to a new set of commitments, a new basis for the practice of science. The extraordinary episodes in which that shift of professional commitments occurs are the ones known to this essay as scientific revolutions. They are the tradition-shattering complements to the tradition-bound activity of normal science......Each [of the great scientific revolutions of the past] necessitated the community's rejection of one time-honored scientific theory in favour of another, incompatible one....And each transformed the scientific imagination in ways that we shall ultimately need to describe as a as a transformation of the world within which scientific work was done. ${ }^{2}$

Ever since I published Rewiring the Corporate Brain in 1997, I have been arguing that new realities facing business were major disruptions of the sort described by Kuhn as heralding scientific revolutions. And in that and subsequent books, ${ }^{3}$ I suggested that a similar revolution in business leadership thinking and practice required that we forget everything we thought we knew about business and focus our minds on an entirely new way of understanding and dealing with the challenges of the twenty-first century. In this book I want to make clear that this required

2 Kuhn, ibid., p. 6.

3 Danah Zohar, Spiritual Capital (2004) and The Quantum Leader (2016). 
revolution is indeed a paradigm shift in the fullest sense of those words, and that this paradigm shift demands a totally new understanding not just of business leadership and practice itself, but also of the human individuals who work in business, the societies in which business operates, and the global community in which we all participate. As I said earlier, every business leader is a person who also needs to lead in his or her own life and personal relationships, and they are also citizens of communities and nations and members of the global community.

Thus, I make the claim that the paradigmatic transformation of business called for in this book has the power to transform the world at all levels of our human experience. The enormity of the paradigm shift required as we move ever deeper into the twenty-first century is a total, radical, reframing that begins at the most basic level of our five senseswhat we see, what we hear, what we smell, those hidden tastes we never noticed, the feeling of another's proximity or touch. We must start again as infants just born into this world, and explore it with eyes of a child, filled with surprise and wonder.

\section{The Exhausted Newtonian Paradigm}

We all learned at school that we should study history because understanding the past would help us better understand where we are now, and what lessons can be learned about how to create a future that does not repeat past mistakes. Thus, it is good to remind ourselves of the defining features of the Newtonian paradigm from which we are now emerging, to realize how these impacted the way we have viewed ourselves and our leadership and, unfortunately, how so many still view the world through their filters.

The Scientific Revolution of the sixteenth and seventeenth centuries, powerfully summarized by Newton's three laws of physics, took the world by storm. Although in many ways Newtonian physics itself built on a 2000 -year-old Western world view that originated in ancient Athens and drew from the monotheism of the West's religions, never before had any single body of work offered to explain Nature so succinctly. Coinciding with the Enlightenment's claims for the unlimited power of Reason, Newton promised that now, not only could we know Nature, but also that we could predict and control her. Knowing the starting position of any particle or object, he said, a knowledge of the forces acting upon it, and equipped with a knowledge of the three laws of motion according to 
which everything in the universe is governed, we could know exactly its future trajectory.

Fate was written not in the stars but rather in the ink with which Newton wrote his equations, and uncertainty was banished forever from our lives. Newton's physics described a world that was simple, lawabiding, and predictable. From the moment that God set the great "clockwork machine" of the universe in motion, the individual, isolated, and impenetrable atoms of which it was made would follow their predetermined destinies. There would be no exceptions, no surprises, certainly no chaos. It was a universe designed by a blueprint, with which scientists could build models and predictive charts, make flow diagrams, and forecasts. A tidy universe that all could understand fully with the objective powers of observation and pure Reason. And though we human beings and our consciousness had no part in this quite dead and lifeless drama, we had the tools fully to control it. Such promise! Such power! The greatest thinkers in fields of thought never before linked to physics took notice and were inspired to emulate Newton in their own work.

Freud, the father of modern psychology, saw Newton's deterministic forces of action and reaction at play in his three-level map of the human mind, a mind whose content and dynamics were determined by the cause and effect of early childhood experience. Newton's impenetrable, isolated atoms became the isolated individuals of Freud's "object relations theory," mere objects to others, incapable of love and imprisoned within their own projections. Freud's work later evolved into Skinner's Behaviorism that portrayed humans as so many laboratory rats and Pavlovian dogs, wholly governed by the iron laws of stimulus and response. And this in turn evolved into the computer models of mind celebrated by today's cognitive and neuroscientists. They tell us we are "mind machines" who are programmed for success or failure, social mimicry, and obedient conventionality. In none of this Newtonian psychology is there room for free will, responsibility, conscious motivation, or personal growth and transformation.

We see here the roots of how workers and employees are treated in our factories and companies today, objects and automatons who must be controlled with power from above by rules and regulations, job descriptions and assignments, often with fear, told what to do, not to be trusted with responsibility or decision making, their muscles and their minds, their "human capital," exploited for profit. And the working lives of most 
of them meaningless, their personal lives, emotions, passions, ambitions, and relationships "nothing to do with the job."

Newton's atoms inspired the social atoms of August Compte's new science of sociology, the atomistic individuals of Locke's and Mills' liberal democracy, and the atomistic nation states of the modern political order. Freud's atomistic and selfish individuals became the businessmen of Adam Smith's capitalism, and the laws and forces of Newton's predictable universe Smith's model for the laws and forces of the predictable capitalist markets. And finally, the Scottish engineer Frederick Taylor took both Newton's machine metaphor of the universe and Weber's Newtonian inspired "iron cage" of bureaucracy as the models for his Scientific Management Theory, known more popularly as "Taylorism."

The Taylorian company, with its all-powerful executive control from the top, its siloed functions and departments, its inflexible bureaucratic rules and regulations and chains of command, its workers and employees who are told what to do and viewed as passive instruments of production, its atomistic sense that it is an isolated island onto itself with no responsibility for community or planet, no regard for ethics or values, consumed by mindless competition in pursuit of maximum profit and share-holder value, is still the model used by most of today's companies. And the management principles needed to run such companies are still the management skills taught by most of the world's business schools.

Is it any wonder that the atomistic and selfish individuals who have learned they are separate from Nature \& separate from others, that the existing capitalist model advocating the ruthless pursuit of self-interest, the dinosaur-like Taylorian company weighed down with bureaucratic structure and atomistic fragmentation and responsible only to its share-holders, and the atomistic nation state that pursues a variation of Trump's “America First!" motto (though perhaps more subtly than Trump himself!), have made a mess of globalization? Can it be any surprise that we now face seemingly insurmountable problems with climate change, identity, inequality, nuclear threat, etc., and can't cope with today's interconnectivity, complexity, diversity, rapid change, and uncertainty?

The Newtonian paradigm worked in its day, just as Newton's physics successfully described the world as scientists understood it then. That physics gave us the technologies of the Industrial Revolution, the bureaucracy and Taylorian management that drew from it gave us the giant 
factories and companies that provided that revolution with its wealthcreating base, and the selfishness and greed of atomistic individualism focused the energy associated with some of the worst of human motives for purposes that at least produced a higher standard of living for larger numbers of people than perhaps ever before. But we realize today all this was at a very great cost, and it doesn't work anymore. It created problems that its own models and mindset cannot solve, and these problems now pose an existential threat to the whole human project. The Newtonian paradigm has exhausted its usefulness, and even its relevance. Something new is needed, an entirely new paradigm is needed.

In science itself, Kuhn points out, the conditions for a paradigm shift occur when experimental data turn up an "anomaly." That is, a result that simply cannot be explained within the framework of the old paradigm. Scientists then begin to ask new, "out of the box" questions that might make some new sense of the inexplicable results. For our present western culture, that anomaly has taken the form of the Covid-19 crisis and the total inability of the existing system and cultural values to meet the life-threatening and economy-busting needs it presented. As Anne-Marie Slaughter described the spontaneous self-organization of new structures, systems, and values in response to the crisis, "The Coronavirus, and its economic and social fallout, is a time machine to the future. Changes that many of us predicted would happen over decades are instead taking place in a span of weeks." 4

One of the unsettling claims made in Kuhn's book was that a new paradigm can never be fully accepted until all the believers in the old paradigm die off. Hopefully, his pessimism was misplaced and there may now be a critical mass of leaders who can embrace a new paradigm and rise both to its challenges and opportunities. And fortunately, there is a new physics, quantum physics, to give this new paradigm its solid conceptual foundations and an overarching framework for helping leaders understand how to build a new and more sustainable personal, business, political, and economic culture within it.

${ }^{4}$ Anne-Marie Slaughter, New York Times, 23 March 2020. 


\section{The New Quantum Paradigm}

Schrodinger's cat is the mascot of the new physics. He was conceived by Erwin Schrodinger, one of the five men who established quantum physics, to illustrate some of the apparently more bizarre and "mind boggling" features of quantum reality.

Schrodinger's cat lives in an opaque box, and the fact that we can't see inside this box is an important part of the story. Inside with the cat is a fiendish device, triggered by the random decay of a radioactive sample that determines whether he is fed good food or poison. If a decay particle hits one switch on the device, the cat gets food. If it hits the other, he gets poison.

In the everyday world of common sense and Newton's physics, one switch or the other would be triggered, the cat would eat either good food or poison, and would be either alive or dead. But Schrodinger's cat is a quantum cat, so things don't work out that way. In the quantum world, all possibilities, even mutually contradictory ones, coexist and have a reality of their own. These coexisting quantum possibilities ensure that the cat is fed both food and poison simultaneously, and he is both alive and dead at the same time.

Of course we never see alive/dead cats, and we can never catch Schrodinger's cat in his double act. If we open the box to look at him, we will find that he is either alive or dead. And this is another curious fact about the quantum world: it is our looking at the cat, our observing him, that determines his fate. According to quantum physics, there is always a dynamic, cocreative relationship between we, the observers, and what we observe. Our very involvement in the act of observing determines the kind of reality that comes into existence. Just these two examples alone from the strange new world of quantum physics - that multiple realities coexist simultaneously, and that it is human observers who influence which of them will then appear as a fact or as an actor in the everyday world of human affairs-have very large implications for the role and responsibilities of leaders. We will see many others as we go along.

A radically new way of thinking runs through the scientific work of the twentieth century. New concepts, new categories, a wholly new vision of physical and biological reality mark a sharp break with nearly everything that science held dear or certain in these past three hundred years. The transition to this new thinking, which I call "quantum thinking," has been so profound that it constitutes a Second Scientific Revolution calling, 
perhaps, for a new scientific method. I shall be arguing in the following chapters that this same quantum thinking will bring about a management revolution, calling for seismic changes in the structure, leadership, and culture of our companies and other social organizations.

Newtonian science was hierarchical. The physical world, like the Taylorian company, was structured into ever-descending units of analysis: Molecules are more basic than complex compounds; atoms are more basic than molecules. Newtonian models of relationship and organization structure power and efficacy on the same ladder of ascending and descending authority. Power radiates out from the center or down from the top.

But the biological "complex adaptive systems" described by complexity science are non-hierarchical. Everything in these systems is connected to everything else and every element of the system is of equally vital importance to the successful working of the system as a whole. Complexity science adapts the principles of quantum physics to living systems. So the systems that complexity science describes are in fact "living quantum systems," and it will be the application of the behavior of complex biological systems to complex human social systems that will form part of our guide for bringing the lessons of the new physics to necessary changes in the leadership and structure of companies. Indeed, Quantum Management Theory is best understood as being a companion to the Santa Fe Institute's pioneering work on complexity economics and other social systems that function as "complex adaptive systems."

Newtonian science stressed continuity and continuous, linear change. The new physics is about abrupt movements and rapid, dramatic, nonlinear change. It is a tale of quantum leaps, catastrophes, and sudden surges into chaos. The constant and the predictable give way to uncertainty and unpredictability. In the hands of quantum or chaos-andcomplexity theorists, Newton's clockwork universe becomes a gambling casino where scientific method must give way to a Monte Carlo method, a computerized rolling of the dice and the calculation of odds.

As we saw, the old science portrayed a physical universe of separate, atomistic parts bound to each other by rigid laws of cause and effect, a universe of things connected by forces and causes. Quantum science gives us the vision of an entangled universe where everything is subtly connected to everything else, where things can be understood only in relationship. Influences are felt in the absence of forces or signals; correlations develop spontaneously; patterns emerge from some order within. 
Where the Newtonian scientist reduced everything to its separate, component parts and a few simple forces acting between them, the quantum or complexity scientist looks for new properties or patterns that emerge when parts combine to form wholes. A universe where nothing new or surprising ever happens is replaced by a self-organizing universe of constant invention. The quantum scientist knows that this fact, or that part, cannot be isolated from its environment, or context. Holism replaces reductionism, and wholes are known to be greater than the sum of their parts. Organized simplicity gives way to self-organized complexity. And, as I have long argued, the quantum scientific paradigm is now giving birth to a more general, all-embracing new quantum paradigm in human affairs.

All the new technologies we use in the twenty-first century are quantum technologies. The silicon chip on which our computers, and all other digital devices, rely, was made possible only through a knowledge of quantum physics. The iPhone lying at my elbow just now, the smart TV I will watch when I finish my day's work, and the internet on which I will check the day's latest news flashes, are quantum technologies. Laser surgery, CAT scans, PET and MRI scans, the medical technologies that diagnose our illnesses and extend our lives, are all quantum technologies. Superfluids and superconductors, the new physics of power systems and the quantum chemistry of materials science-all harness the secrets of quantum science. And now quantum biologists are telling us that our bodies rely on quantum processes within their cells, and neuroscientists are finding quantum processes at work in our brains. The flocking patterns of birds in flight and the photosynthesis of plants rely on quantum signals and processes, and complexity scientists tell us that our cities do, and our companies could, operate according to the same quantum laws as the universe itself. We live in a Quantum Age now, within a newly emerging quantum paradigm, and the companies and organizations that will succeed, and the leaders who will manage them, must be quantum companies and quantum leaders. We must all master quantum thinking. And hence I offer this book.

Readers will not be asked to understand quantum physics itself. That requires very advanced mathematical understanding and is only of practical use to other scientists and to people developing new technologies that rely on it. My purpose in this book is to outline the paradigmatic implications of quantum physics, the "big ideas" that make a quantum paradigm different from the old Newtonian one, and how these apply 
to the challenges and opportunities facing and available to leaders today. This can be done clearly, in simple language that non-scientists can easily understand.

This book is written in five parts, but these are "quantum parts." This means that every theme in the book is an element of the larger whole, every theme is connected to every other and is necessary to understanding the full implications of every other. It is a book addressed to leaders, but as we shall see, I believe that each of us is a leader at some level of our lives, the true masters and makers of our own individual lives, and many are the leaders of families, companies, communities, and nations. And thus, the new paradigm being offered in this book is a new paradigm for living, thinking, learning, leading, and organizing ourselves in our shared world, which each of us helps to create and for which each of us is responsible.

Open Access This chapter is licensed under the terms of the Creative Commons Attribution-NonCommercial-NoDerivatives 4.0 International License (http:// creativecommons.org/licenses/by-nc-nd/4.0/), which permits any noncommercial use, sharing, distribution and reproduction in any medium or format, as long as you give appropriate credit to the original author(s) and the source, provide a link to the Creative Commons license and indicate if you modified the licensed material. You do not have permission under this license to share adapted material derived from this chapter or parts of it.

The images or other third party material in this chapter are included in the chapter's Creative Commons license, unless indicated otherwise in a credit line to the material. If material is not included in the chapter's Creative Commons license and your intended use is not permitted by statutory regulation or exceeds the permitted use, you will need to obtain permission directly from the copyright holder.

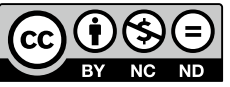

